\title{
Physical activity for all: new research highlights health benefits
}

\author{
Kimberly G Harmon
}

Keeping people active is a major focus of sports medicine professionals. Regular exercise helps reduce the incidence of diabetes, hypertension, cancer, depression and osteoporosis. However, recent articles in the lay press have questioned the benefits of exercise, specifically whether or not exercise helps you lose weight (http://www.time.com/time/health/article/0,8599,1914857,00.html). Sports, fitness and exercise professionals, including the American Medical Society for Sports Medicine (AMSSM), have taken strong exception to that peculiar interpretation of the evidence. In a world where the direct results of obesity and physical inactivity result in an estimated $\$ 147$ billion dollars (US) in health care cost in the United States alone, ${ }^{1}$ the last thing people need is another excuse not to exercise. In this issue, Dr Neil King and colleagues from Professor John Blundell's lab in Leeds report that exercise provides important health benefits independently of weight loss $^{2}$ (see page 924). The issue also highlights that exercise is beneficial for people of all shapes, sizes and ages!

\section{FIT YOUTH . . . FIT ADULT}

In a systematic review, Jonatan Ruiz ${ }^{3}$ (see page 909) provides convincing evidence that being physically fit as a child and an adolescent provides long-term cardiovascular benefits later in life, suggesting not only that exercise is good, but that exercise in young people is particularly good. Individuals who were more fit had better blood lipid profiles and blood pressure, and less adiposity later in life. Conversely, those who had higher BMI had an increased risk of death. The number of children who are overweight $(16 \%)$ or obese $(13 \%)$ and don't meet recommended activity guidelines (65\%) continues to rise (Youth Risk Behavior

Correspondence to: Dr K G Harmon, Box 354410 , University of Washington, Seattle, 98125, USA; kharmon@u.washington.edu
Survey 2007, http://www.cdc.gov/ HealthyYouth/yrbs/pdf/yrbs07_us_overview.pdf). Ruiz provides compelling reasons to reverse that trend.

\section{YOUTH OR ADULT?}

Although some children spend too much time on the couch, some elite youth athletes who train vigorously will reach international levels of competition. Although the long-term health of these athletes is good, ${ }^{4}$ the question of just how old or young they are can be more difficult to answer than it may initially seem. In a provocative editorial, FIFA's Professor Jiri Dvorak brings to light the interesting concept of "age doping", where the age of an athlete is either unknown or falsified to provide a competitive advantage in age-restricted competitions $^{5}$ (see page 884). Keeping young people active and motivated through sporting competition is important. Sports medicine is playing a critical role if it can contribute to preserving the fairness of that competition.

\section{EXERCISE IS EVEN GOOD FOR THOSE WHO ARE ALREADY OVERWEIGHT AND OBESE}

It would be ideal if all children were fit and active and this led to a world of healthy, ideal-weight adults. However, a quick glance around the mall reveals that this is not the case. Recommending exercise to those who are already overweight or obese can sometimes be daunting. This issue introduces a simple system for exercise prescription in this group ${ }^{6}$ (see page 951). The Activity Point System (APS) is based on the Dr Barb Ainsworth's Compendium of Physical Activity. The APS gives an accurate way to quantify and track physical activity in heavier individuals and draws attention to the fact that many everyday actions should be included in activity calculations. Tracking physical activity can motivate and energise an individual to sustain an exercise programme, and, as has been repeatedly pointed out, exercise is good for just about everyone.

The importance of sound scientific and medical knowledge is invaluable in taking care of athletes and active individuals and in providing reasons for those who aren't active to become active. This knowledge is also important for debunking health misinformation and for informing public health policy. The AMSSM and BJSM will continue to partner to bring you the latest clinically relevant research and to positively impact the health of all.

\section{CANCUN 2010 - AMSSM ANNUAL MEETING!}

On that note of continuing education, AMSSM is committed to fostering research, furthering education and providing a collegial atmosphere for its members. I invite you to consider our next annual meeting from 17 to 21 April 2010 in the resort town of Cancun, Mexico. We showcase cuttingedge, clinically relevant content and encourage research submissions. Our meetings have increasingly benefited from international participants and, to encourage this further, AMSSM extends its member conference registration rate to all non-North Americans.

Competing interests: Kimberly Harmon is the President of the American Medical Society for Sports Medicine and a BJSM Associate Editor.

Br J Sports Med 2009;43:883.

doi:10.1136/bjsm.2009.068148

\section{REFERENCES}

1. Finkelstein EA, Trogdon JG, Cohen JW, Dietz W. Annual medical spending attributable to obesity: payerand service-specific estimates. Health Aff (Millwood) 2009;28:w822-w831.

2. King NA, Hopkins $M$, Caudwell $P$, et al. Beneficial effects of exercise: shifting the focus from body weight to other markers of health. Br J Sports Med 2009; 43:924-7

3. Ruiz JR, Castro-Piñero J, Artero EG, et al. Predictive validity of health-related fitness in youth: a systematic review. Br J Sports Med 2009;43:909-23.

4. Kujala UM, Kaprio J, Sarna S, Koskenvuo M. Relationship of leisure-time physical activity and mortality: the Finnish twin cohort. JAMA 1998;279:440-4.

5. Dvorak J. Detecting over-age players using wrist MRI: science partnering with sport to ensure fair play. Br J Sports Med 2009;43:884.

6. Ehrsam R, Hoerler-Koerner U, Stoffel S, et al. Exercise prescription for the overweight and the obese: how to quantify and yet keep it simple. Br J Sports Med 2009; 43:951-3.

7. Ainsworth BE, Haskell WL, Leon AS, et al. Compendium of physical activities: classification of energy costs of human physical activities. Med Sci Sports Exerc 1993;25:71-80. 